\title{
A Contrastive Study of Chinese and British English Request Modifications
}

\author{
Xiuping Han \\ Binzhou Medical University, YanTai, China \\ Email: Xiuping_han@126.com
}

\begin{abstract}
This study is a contrastive one on the speech act of request in British English and Mandarin Chinese. It investigates the similarities and differences in request modifications used by native speakers of both languages on the bases of nine designed situations. The choice of modifications in each situation is determined to some degree by the social variables of power and distance. However, a deeper reason lies in the different cultural backgrounds of the two different languages.
\end{abstract}

Index Terms - request modifications, contrastive study, external modification, internal modification

\section{INTRODUCTION}

With the rapid development of science and technology, people from different countries and cultural backgrounds are making more and more communications, and as a consequence, much attention has been paid to the politeness strategies in cross-cultural communication. Nowadays, politeness is also a very important subject of research in pragmatics and sociolinguistics.

This study investigates request strategies based on data from Mandarin Chinese and British English, identifying the similarities or differences between the understandings of politeness by native speakers of both languages. By studying the expression of politeness through the speech act of request, we try to find pre-conceived ideas of rudeness or politeness associated with certain cultures' linguistic behavior as well as their cultural roots.

A head act is the minimal unit which can realize a request. In other words, it is the core of the request sequence. For the realization of a request, the head act is important. However the success of the requests does not necessarily rely on the appropriateness of the head act. Modifiers within a request, play the decisive role (Sifianou, 1992) as well. The possible external and internal modifications function as a way of upgrading or intensifying and downgrading or softening the impact of the request. We will have a brief analysis of the types of request modification used in BE and $\mathrm{CH}$ throughout all nine situations.

\section{A. Purpose of the Study}

The main objective of this study is to explore politeness by investigating the patterns of request speech acts produced by native speakers of Mandarin Chinese and British English under the influence of social factors, with the term 'native speaker' referring to the participants in the survey who speak Mandarin Chinese or British English as their mother tongue. Specifically speaking, this study focus on the choice of patterns in the use of internal modifications, and external modifications,

A speech act of request commonly involves a number of social, cultural, and situational factors which usually produces sensitivity in both interlocutors. The effects of social variables such as power status and familiarity are crucial for the realization of request speech acts, and these factors also determine how speakers from different cultures recognize and adapt to the realization patterns of requests (Brown and Levinson 1987). With a view to identifying the specific influences of the two social factors on the request speech act, this study also analyzes these speech acts in terms of power status and familiarity.

\section{B. Methodologies for Data Collection}

The most commonly used data collection method in the study of cross-cultural communication or inter-language pragmatics is the written questionnaire, and DCT is the favored and most widespread instrument to obtain targeted speech acts. It has been employed by many researchers to examine the performance of the request speech act. DCT is efficient, because the short time-consumption required for material allows an experimenter to obtain large amounts of data, but as has been pointed out in the literature, including Blum-Kulka(1985), Blum-Kulka and Olshtain (1984), Hong (1998), and Lee-Wong (2000), there are many limitations involved in the use of questionnaires. It is difficult for participants to distinguish between an expression which they imagine they would use to respond in a given situation, and the actual speech produced in a real spoken situation. Written responses may not actually correspond with oral performance in real life. Furthermore, they may not reveal pragmatic features of spoken interactions.

Role-play has been used as a means of collecting spoken data in this study of cross-linguistic and inter-language pragmatics. Responses in role-play are recorded by audio taping, and are then transcribed. The role-play instrument 
allows researchers to obtain more interactive data. Moreover, it allows participants sufficient time to respond; thus researchers can obtain more interactive data.

Role-play has been employed in two ways: closed role-play and open role-play. In closed role-play, one participant responds verbally to a given situation without a reply from the other. This study employs the means of open role-play which allows participants to interact, and offers more conversational features such as the sequences of an action, the process of negotiation, hesitation, turn-taking, or nonverbal items of speech production. Trosborg (1995) states that the data elicitation instrument of open role-play allows a full examination of the sequences of negotiation for achieving requests, which results in the realization of complete request interactions.

The open role-play was constructed in English and Chinese and performed by 16 native speakers of British English ( 9 males and 7 females) and 20 native speakers of Chinese (10 males and 10 females) respectively. All of the Chinese informants were university students doing their first degree in a subject not related to languages or linguistics. Most of them were between 18 and 25 years of age. The English participants were comprised of college teachers (5), university students (9), and office workers from some companies (2). Most of the English participants were between 18 and 33 years of age. For each situation, the participants were matched in pairs in random and their conversation was recorded for further analysis.

TABLE I

REQUEST MODIFICATION IN THE NINE SITUATIONS (BE: BRITISH ENGLISH; CH: CHINESE)

\begin{tabular}{|c|c|c|c|c|c|c|c|c|c|c|c|c|c|c|c|c|c|c|}
\hline \multirow{2}{*}{$\begin{array}{l}\text { Type size (pts.) } \\
\text { External } \\
\text { modification }\end{array}$} & \multicolumn{2}{|l|}{$\mathrm{R} 1$} & \multicolumn{2}{|l|}{$\mathrm{R} 2$} & \multicolumn{2}{|l|}{ R3 } & \multicolumn{2}{|l|}{$\mathrm{R} 4$} & \multicolumn{2}{|l|}{ R5 } & \multicolumn{2}{|l|}{ R6 } & \multicolumn{2}{|l|}{$\mathrm{R} 7$} & \multicolumn{2}{|l|}{$\mathrm{R} 8$} & \multicolumn{2}{|l|}{ R9 } \\
\hline & $\mathrm{BE}$ & $\mathrm{CH}$ & $\mathrm{BE}$ & $\mathrm{CH}$ & $\mathrm{BE}$ & $\mathrm{CH}$ & $\mathrm{BE}$ & $\mathrm{CH}$ & $\mathrm{BE}$ & $\mathrm{CH}$ & $\mathrm{BE}$ & $\mathrm{CH}$ & $\mathrm{BE}$ & $\mathrm{CH}$ & $\mathrm{BE}$ & $\mathrm{CH}$ & $\mathrm{BE}$ & $\mathrm{CH}$ \\
\hline Preparator & 11 & 10 & 8 & 9 & 12 & 5 & 8 & 6 & 4 & 9 & 10 & 13 & 9 & 3 & 4 & 1 & 3 & 4 \\
\hline Reason & 11 & 13 & 15 & 14 & 12 & 8 & 5 & 12 & 15 & 10 & 13 & 15 & 14 & 9 & 8 & 6 & 2 & 0 \\
\hline Disarmer & 9 & 4 & 6 & 4 & 5 & 0 & 7 & 5 & 9 & 7 & 4 & 1 & 6 & 1 & 2 & 3 & 1 & 0 \\
\hline $\begin{array}{l}\text { Getting a } \\
\text { precommitment }\end{array}$ & 1 & 3 & 8 & 9 & 0 & 0 & 2 & 5 & 12 & 5 & 4 & 0 & 0 & 0 & 0 & 0 & 0 & 0 \\
\hline $\begin{array}{l}\text { Promise of } \\
\text { reward }\end{array}$ & 0 & 1 & 1 & 3 & 0 & 1 & 0 & 2 & 1 & 4 & 5 & 8 & 0 & 0 & 5 & 2 & 0 & 0 \\
\hline Cost minimizer & 5 & 6 & 0 & 2 & 0 & 0 & 3 & 7 & 1 & 0 & 0 & 0 & 0 & 6 & 1 & 2 & 0 & 0 \\
\hline \multicolumn{19}{|l|}{$\begin{array}{l}\text { Internal } \\
\text { modification }\end{array}$} \\
\hline Downtoner & 7 & 5 & 10 & 6 & 9 & 13 & 5 & 6 & 9 & 8 & 6 & 15 & 8 & 9 & 6 & 11 & 9 & 15 \\
\hline Hedge & 2 & 3 & 0 & 2 & 0 & 0 & 0 & 2 & 0 & 2 & 0 & 2 & 3 & 0 & 3 & 0 & 2 & 0 \\
\hline $\begin{array}{l}\text { Politeness } \\
\text { marker }\end{array}$ & 5 & 2 & 4 & 1 & 4 & 0 & 3 & 1 & 6 & 3 & 2 & 1 & 5 & 1 & 3 & 0 & 0 & 0 \\
\hline Appealer & 1 & 10 & 0 & 4 & 2 & 3 & 1 & 9 & 1 & 4 & 1 & 7 & 3 & 5 & 3 & 1 & 2 & 0 \\
\hline No. of requests & 15 & 17 & 15 & 16 & 15 & 15 & 14 & 15 & 15 & 17 & 15 & 15 & 15 & 17 & 15 & 15 & 15 & 18 \\
\hline
\end{tabular}

\section{EXTERnAl MODIFICATION (SUPPORTIVE MOVES)}

External modification is also called supportive moves. It is not a part of head acts, but it often precedes or follows a head act. They are used to mitigate or aggravate a request act. The most frequent external modifiers found in the data in decreasing order are: reasons, preparators, disarmers, enquirers and getting pre-commitments, promise of reward, cost minimizer.

This type of modification is achieved through the use of optional clauses which either mitigate or emphasize the force of the whole request. Most external modifiers are means by which the speaker tries to get the addressee to support the actual request. Sometimes single external modifiers or a combination of them are used with the purpose of not uttering the request but allowing the addressee to offer.

\section{A. Reasons}

Reasons or grounders as they have been usually called are clauses which can either precede and/or follow a request head act. They are the most preferred external modification. As illustrated by the term the speaker gives reasons or justifications to support his/her request. The following examples come from R1 and R6.

"I have many bills to pay and they are rather urgent. Could you give me my salary in advance or lend me some money?"

“这个项目实在太重要了，你那个假期呢，咱们能不能往后拖一拖?”

The use of reasons or grounders can be seen as a co-operative strategy towards harmonious exchanges since by giving reasons the speaker expects addressee to be more understanding and willing to co-operate. According to Brown and Levinson (1987) asking for and giving reasons for a speech act is a 'positive' politeness strategy in that it 'is a way of implying "I can help you" or "you can help me", and, assuming cooperation, a way of showing what help is needed'. It could be counter argued, however, that by giving reasons the speaker is showing consideration for the addressee, providing a 'good enough' stance from which to ask the addressee to his/her course of action in order to help the speaker. Thus the giving and asking for reasons could either be related to 'positive' and/or demonstrated in studies of other languages, stand out as the single most frequent supportive move. 


\section{B. Preparators}

Preparators, another type of supportive move, constitute the second most preferred external modification by speakers of both languages. They are used by the speaker in order to prepare the addressee for the ensuing request. The speaker usually announces that $\mathrm{s} / \mathrm{he}$ will be making a request either by means of checking the addressee's availability for carrying out the request or by asking the addressee for permission to make the request. It should be noted that in doing so the speaker does not tell the addressee the content of the request and does not, necessarily, get a positive commitment from him/her.

"I need to ask you a really big favor. My car's just broken down and I need to pick my parents up from the airport. It's really desperate that I can't pick her up. Is it possible I could borrow your car just for a few, just half an hour?" (R2)

“我有个麻烦事需要您帮忙考虑一下, 我目前的工作对我来说有些困难, 您看, 能不能您给我帮忙协调一 下?” (R7)

\section{Disarmers}

Disarmers are all the possible external modifying devices which 'disarm' addressees from the possibility of refusal. In other words, the speaker tries to remove any potential objections the addressee might raise upon being confronted with the request. Disarmers may include formulaic promises, complimenting phrases, and most specifically clauses that express the speaker's awareness and concern that the request might be deemed as an imposition on the addressee.

"I'm sorry to bother you. We don't know each other very well. I know we're neighbors and everything would it be possible for you to help me move my things out of my flat? Would that be OK? ..." (R5)

“不好意思，麻烦您一下，我就住在隔壁，你有没有时间帮我搬点东西?”

As shown in Table 6 there is almost a 50\% difference in the use of the disarmers by British and Chinese informants. The Chinese show a very low incidence of the device. The device was used by the British in almost all the situations of the role-play. And the British use of the device does not seem to be motivated by differences in social status between the interlocutors.

\section{Getting Pre-commitments}

According to Edmondson (1981), Getting pre-commitments fall into the group of what has been described as commitment-seeking devices (Edmondson, 1981). They are part of what he calls 'pre-exchanges' since the outcome of such an exchange will directly lead to the beginning of the head act. Although such pre-sequences do not oblige the hearer to give either a positive or a negative response, speakers do not tend to expect negative responses and sometimes not even a response at all. When an answer is given by the hearer it expresses the level of his/her commitment. Getting a pre-commitment helps the speaker feel s/he has a 'safer' ground for uttering his/her request. In terms of the frequency of use of this commitment-seeking device, it is interesting to note that the British employed it more often than the Chinese.

"I was wondering if you could do me a big favor. I was wondering whether I could borrow your car for about two hours." (R2)

The Chinese use a lot of pre-commitments in R1 than the British.

“你能帮我个忙吗? 我最近经济状况很紧张, 实在是没办法了, 我来就是来看看您能不能让我预支一部分薪 水,我会尽快补上的。”

\section{E. Promise of Reward}

Promise of reward, another type of supportive move, is employed by speakers in order to increase the likelihood of the hearer's compliance. This strategy is achieved by announcing a reward which will be given to the addressee upon fulfillment of the request. As can be seen, the device has a low incidence in both languages. Whereas the British employed it in R5 and R7, more Chinese employed it in R1 and R6 which probably due to the situational factors, in that the addressee was asked to postpone or cancel his/her holiday and thus some kind of reward was considered necessary to get him/her to comply with the request. Here are some examples:

"I'm sorry to bother you. We don't know each other very well. I know we're neighbors and everything would it be possible for you to help me move my things out of my flat? Would that be OK? ... And obviously likewise in the future I'll be doing the same for you if ever you need me to.” (R5)

“这个项目实在太重要了, 你那个假期呢, 咱们能不能往后拖一拖? 等这阵儿忙完了, 我给你多补几天假 期!?(R6)

\section{F. Cost Minimizer}

Cost minimizer is preferred by the speakers to minimize the hearer's cost of the request. This strategy has a high incidence in some situations, such as R1, R4 by both the British and Chinese participants, and situation 7 by Chinese participants, when the speaker attempts to reduce the burden of the request on the hearer. Here are some of the examples

“我明天就还你。”(R1)

"I will return it to you tomorrow." (R1) 
“不是说马上就要换,这个可能就是说,我想征求一下您的意见,这个时间的话,看您来协调安排,我也会尽量不影 响工作.”(R7)

\section{INTERNAL MODIFICATIONS}

Internal modification is part of head acts, and plays a role in minimizing or intensifying the illocutionary force of a request act, as a downgrader or upgrader. Whereas external modification is achieved by intensifying or mitigating devices occurring in the immediate context of the speech act, internal modifications occur within the speech act itself. As with external modifications they can either soften or aggravate the force of the act (Faerch \& Kasper, 1984). BlumKulka(1985) distinguish between two types of internal modifications: syntactic and lexical/phrasal downgraders. The former are choices between different grammatical structures, interrogative versus, imperative constructions, conditional constructions, negation and tenses. The latter comprise a large number of mitigating devices such as politeness markers, hedges, diminutives and the like. In this section we will only consider lexical and phrasal downgraders.

The most frequently used internal modifiers found in the data can be seen in Table 6. As can be seen in this table, British requests show a very high incidence of internal modifications overall compared to Chinese requests. Whereas more than $90 \%$ of British English requests are internally modified, only $45 \%$ of Chinese requests are. This greater preference for internally modified requests by the Britons makes their requests more tentative, showing more of an inclination towards considering the addressee's freedom of action. Below we will have a brief analysis of the different kinds of internal modifiers.

\section{A. Downtoners}

Downtoners are propositional modifiers used by the speaker with the purpose of modulating the impact his/her request is likely to have on the addressee. Examples of the use of the device can be seen in the following examples:

"I wonder if there is any possibility I could borrow your car to go and pick my parents up from the airport."(R2)

"I was wondering if you could possibly postpone it, give the tickets back."(R6)

"I was wondering if you could perhaps help me." (R5)

As can be seen in Table 6, in English the use of downtoners is the most frequent internal modifier. The use of downtoners helps make the request more tentative, that is to say help to soften its impact. It could be said that downtoners belong to the realm of 'negative' politeness since they show the speaker does not either assume that the addressee will/has to comply with the request or coerce the addressee into complying with the request. The Chinese also use a lot of particles, such as le(了), ne(呢), ba(吧), ma(嘛), to minimize the impact of request.

“你那个假期呢, 还是往后拖一拖吧?”

\section{B. Hedges}

Hedges have been defined as adverbials used by speakers when they wish to avoid a precise propositional specification. According to Brown and Levinson (1987): a 'hedge' is a particle, word, or phrase that modifies the degree of membership of a predicate or noun phrase in a set; it says of the membership that it is partial, or true only in certain respects, or that is more true and complete than perhaps might be expected. Examples of hedges are the use of 'somehow', 'kind of', 'sort of' and 'at all' in requests. As can be seen in Table 6 they had a very low incidence in English and were also used little in Chinese.

The Chinese also use many vague expressions to tone down and avoid potential provocation of the request. For example, dagai (大概 'perhaps'), sihu (似乎 'seem'), keneng (可能 'possibly/probably'), you keneng (有可能 'possibly').

\section{Politeness Markers}

Polite and respectful expressions are added to the request to seek cooperation from the hearer. We use it to describe the use of 'please' in English. While in Chinese, people usually use qing (请'please'), laojia (劳驾 'excuse me'), baituo (拜托 'please'). Terms of address as politeness markers are also used. For example, xiansheng (先生 'Sir'), xiaojie (小 姐 'Miss'). There is a higher incidence of the device in British English. However, the device was only employed nine times in Chinese. Conclusion thus can be derived from the data that the frequency of using this polite marker in Chinese request is much lower than that in English request. In Chinese, when “请”, this polite marker is added, the request is often practiced between speaker and addressee whose relationship is not intimate.

\section{Appealer}

Appealer is used a lot among Chinese participants, while it has a very low incidence in English. Appealer is used to appeal to the hearer's understanding and to elicit a response. It is used at the end of a sentence, often in the form of a tag question. For example, in Chinese, “xing ma? (...行吗?)”, “ keyi ma? (... 可以吗?)”, “ hao ma? (...好吗?)”, and“xingbuxing? (... 行不行?)”, all mean '...OK?'in English.

“I'm sorry to bother you. We don't know each other very well. I know we're neighbors and everything would it be possible for you to help me move my things out of my flat? Would that be OK?'(R5) 
“我借用一下你的电脑, 可以吗?”(R3)

\section{CONCLUDING REMARKS}

\section{A. Internal Modifications}

As can be seen from the above examples, British requests show a very high incidence of internal modifications overall compared to Chinese requests. Whereas more than $90 \%$ of British English requests are internally modified, only $40 \%$ of Chinese requests are. This greater preference for internally modified requests by the Britons makes their requests more tentative, showing more of an inclination towards considering the addressee's freedom of action.

The internal modifications that have been discussed in details include downtoners, appealer, politeness markers and hedges. Downtoners are the most frequent internal modifier in English especially when the interlocutors are not familiar with each other, regardless of the social power. Since Chinese speakers tend to use the direct strategy in some situations, they also have to use a lot of particles, such as $l e$ (了), ne(呢), $b a$ (吧), $m a$ (嘛), to minimize the impact of request. The Chinese also use many vague expressions to tone down and avoid potential provocation of the request. So the use of hedges has a high incidence in Chinese than in English. There is a higher incidence of the politeness markers in British English. In Chinese, when the polite marker “请” is added, the request is often practiced between speaker and addressee whose relationship is not intimate. Appealer is used a lot among Chinese participants, while it has a very low incidence in English. That's also because Chinese speakers prefer the direct strategy in many situations, they use a lot of tag questions such as “xing ma? (...行吗?), hao ma? (...好吗?)", in order to minimize the impact of imposition. These results of study also show the impact of social variables on the choice of lexical modifications in both British English and Chinese.

\section{B. External Modifications}

According to the studies of Blum-Kulka \& Olshtain (1984), both native English speakers and Chinese speakers tend to use more supportive moves in their requests when the imposition of the request is high. The reason is that supportive moves are employed to show politeness. Since request is itself an "impolite" act, so to minimize the degree of impoliteness turns out to be much important when requests are made. One way out is to use supportive moves to mitigate the face threatening impact.

According to Brown \& Levinson's face theory, each person has a positive face and a negative face. Positive face refers to the need to be accepted and approved by others while negative face refers to the need not to be imposed by others, especially to have one's own freedom of action. To request somebody to do something means to impose the requested act on the hearer, so it would be a threat to the hearer's negative face. In order to show politeness and facilitate the requested act, requestors will usually adopt supportive moves.

According to Leech's politeness principles, people need to observe the tact maxim when making requests, i.e. to minimize the cost to others and maximize the benefit to others. There is also why people usually give promises of reward and minimize the imposition in their requests.

In the Chinese polite system,

politeness principles also explain why more supportive moves are used when the imposition of the requested act increases. According to Gu's "virtue-word-deed maxim", "In action, efforts should be made to minimize the cost to other people, simultaneously, to maximize the benefit to other people. In language, to maximize the benefit other people give and to minimize the cost self pay."

Out of the need of politeness, both native Chinese speakers and native English speakers will adopt supportive moves to minimize the cost to the addressee or to minimize the imposition on his/her freedom of action. The use of supportive moves consequently makes requests more polite and at the same time more effective. From this point of view, native Chinese and English speakers are the same. However, there are also many differences as to how to use supportive moves in the requests both in English and Chinese.

In the western society, people emphasize doing things by themselves and avoid imposing on others. Closely related to individualism is the value of equality, the freedom of individuals. To request others to do something means to impose and that will be an interference of other people's freedom. Hence, this harms the negative face of the addressee, which is very much stressed in English-speaking countries. In order to save the addressee's negative face, native English speakers will adopt supportive moves to reduce the impact of imposition. As we can see, westerners may care more about the negative face.

Out of the consideration of "face", Chinese people tend to be more careful than native English speakers when making requests because the Chinese society is a collective one. Once one loses his/her face or causes others to lose face, it would be very hard for him/her to live in the community any more. Face is so important to the Chinese people that everyone in the society will try his/her best to save it and at the same time not to lose it. Chinese people loves their own face; they also respect other people's face and try to avoid harm other people's face. Otherwise, others will give them no face and that will be very embarrassing. We can find that in Chinese requests, there are usually more supportive moves than in English requests. Another reason why there are more supportive moves in Chinese requests is that 
Chinese people like to use imperatives to make requests In order to reduce the abruptness and achieve politeness; supportive moves need to be adopted.

\section{REFERENCES}

[1] Austin, J. L. (1962). How to Do Things with Words. Oxford: Oxford University Press.

[2] Brown, P. and S. Levinson (1987). Politeness: Some Universals in Language Use. Cambridge: Cambridge University Press.

[3] Edmonson, W. (1981). Spoken Discourse. London: Longman.

[4] Blum-Kulka, S. (1985). Modifiers as indicating devices: the case of requests. Theoretical Linguistics,12 (2-3), $213-229$.

[5] Blum-Kulka, S. and E. Olshtain. (1984). Requests and apologies: A cross-cultural study of speech act realization patterns. Applied Linguistics, 5,196-213.

[6] Fukushima, S. (1996). Requests strategies in British English and Japanese. Language Sciences,18, 671-688.

[7] Fukushima, S. (2003). Requests and Culture: Politeness in British English and Japanese. Bern: Peter Lang.

[8] Faerch, C. and G. Kasper. (1984). Internal and external modification in interlanguage request realisation. In Blum-Kulka, S., J. House and G. Kasper (eds.). Cross-Cultural Pragmatics: Requests and Apologies. Norwood NJ: Albex, 221-247.

[9] Hong, W. (1998). Request Patterns in Chinese and German: A Cross-cultural Study. Munich: Lincom Europa.

[10] Lee-Wong, S.M. (2000). Politeness and Face in Chinese Culture: Cross Cultural Communication. Melbourne: Monash University Press.

[11] Sifianou, M. (1992). The use of diminutives in expressing politeness: Modern Greek versus English. Journal of Pragmatics,17 (22), 155-173.

[12] Trosborg, A. (1995). Interlanguage Pragmatics: Requests, Complaints and Apologies. Berlin: Mouton de Gruyter.

[13] Gu, Y. (1990). Politeness phenomena in modern Chinese. Journal of Pragmatics 14 (2),237-257.

[14] Leech, G. (1983). Principles of Pragmatics. London: Longman.

[15] Goffman, E. (1967). Interaction Ritual: Essays on Face-to-Face Behaviour. New York: Doubleday Anchor Books.

Xiuping Han, born in Binzhou, Shandong province, China, in 1980,12, with a master's degree in Literature (2010) from Ludong University, Yantai, Shandong Province. The major field of study is pragmatics.

She now works in Binzhou Medical College as an English teacher, with many papers concerning English language study and language teaching published. 